\title{
The relationship between redox enzyme activity and electrochemical potential-cellular and mechanistic implications from protein film electrochemistry
}

\author{
Andrew J. Gates, Gemma L. Kemp, Chun Yip To, James Mann, Sophie J. Marritt, \\ Andrew G. Mayes, David J. Richardson and Julea N. Butt*
}

Received 16th December 2010, Accepted 17th February 2011

DOI: $10.1039 / \mathrm{c0cp} 02887 \mathrm{~h}$

In protein film electrochemistry a redox protein of interest is studied as an electroactive film adsorbed on an electrode surface. For redox enzymes this configuration allows quantification of the relationship between catalytic activity and electrochemical potential. Considered as a function of enzyme environment, i.e., $\mathrm{pH}$, substrate concentration etc., the activity-potential relationship provides a fingerprint of activity unique to a given enzyme. Here we consider the nature of the activity-potential relationship in terms of both its cellular impact and its origin in the structure and catalytic mechanism of the enzyme. We propose that the activity-potential relationship of a redox enzyme is tuned to facilitate cellular function and highlight opportunities to test this hypothesis through computational, structural, biochemical and cellular studies.

\section{Introduction}

Jaroslav Heyrovský is widely credited with being the first to demonstrate the utility of dynamic electrochemistry. While studying electrocapillarity using a mercury drop electrode he established that the relationship between surface tension and electrode potential was sensitive to the identity of ions in the surrounding electrolyte. ${ }^{1}$ This suggested that the flow of current in an electrolytic cell would provide insight into chemical and electrochemical processes occurring at the electrode and Heyrovský was quickly able to demonstrate that this was the case. Not only could reversible redox transitions of species in solution and adsorbed on electrodes be detected but redox coupled ligation and electrocatalysis could also be readily identified. Consequently there was much discussion of Heyrovskýs results and theoretical treatments of various electrochemical mechanisms emerged that allowed the relevant thermodynamic and kinetic parameters to be extracted from such data. Thus, this dynamic electrochemistry distinguished itself from potentiometric measurements of electrochemical potential at zero current, i.e., systems at equilibrium, and rapidly became established as a cornerstone of analytical methods.

Heyrovský received the 1959 Nobel Prize for Chemistry in recognition of his contributions to electrochemistry. ${ }^{2}$ This was a time when the importance of electron transfer and electrocatalysis in biology, most obviously in respiration and

Centre for Molecular and Structural Biochemistry, School of Chemistry and School of Biological Sciences, University of East Anglia, Norwich Research Park, Norwich, NR4 7TJ, UK.

E-mail:j.butt@uea.ac.uk photosynthesis, was attracting much attention. There was an understandable desire to apply dynamic electrochemistry to the study of redox active proteins. However, initial attempts frequently produced results that were hard to reconcile with those obtained in established biochemical analyses. The breakthrough came in the 1970s when three groups established conditions that allowed the native state of a redox protein to approach an electrode with sufficient proximity and the appropriate orientation to support facile and direct interfacial electron exchange. ${ }^{3-5}$ Numerous proteins have now been studied by dynamic electrochemistry producing results that have quantified not only behaviour recognisable to the biochemical community but also new facets of protein activity.

A number of excellent reviews have described various aspects of protein electrochemistry, from the experimental details through to the information that it affords, e.g. ref. 6-13. Consequently, this Perspective takes the opportunity to highlight some of the challenges and opportunities we see arising from the current state of the art in the dynamic electrochemistry of redox enzymes. Our particular focus will be the relationship between enzyme activity and electrochemical potential. This relationship is most readily resolved when the enzyme of interest is adsorbed on an electrode surface in an approach termed protein film voltammetry (PFV) or protein film electrochemistry (PFE). Thus, we begin by introducing PFE of a nitrate reductase that provides a convenient focus for our discussions. We then consider the nature of the activitypotential relationship both in terms of its cellular impact and its origin in the structure and catalytic mechanism of the enzyme highlighting as we go along some areas where new insights would be beneficial. 


\section{Redox enzyme activities with protein-film electrochemistry (PFE)}

A schematic of the PFE experiment as it may apply to the nitrate reductase NapAB that is located in the periplasmic compartment of a phylogenetically diverse number of bacterial species including the enteric bacterium Escherichia coli and the soil bacterium Paracoccus pantotrophus is illustrated in Fig. 1. In essence, the protein of interest is adsorbed as a (sub-) monolayer film on an electrode surface. Within this film the protein molecules participate in direct exchange of electrons with the electrode and retain their biochemically recognisable functionality which for NapAB is the catalytic reduction of nitrate to nitrite. Electrodic reduction of NapAB is followed by the chemical oxidation of NapAB that accompanies nitrate reduction and this in turn allows more electrons to be delivered to NapAB from the electrode. The result is a continuous flow of negatively signed catalytic current with a magnitude that quantifies the rate of substrate $\dagger$ reduction by the enzyme film at any moment, since Amperes can be related to the rate of substrate transformation through knowledge of the Faraday constant and the number of electrons required to turn substrate into product(s). Most significantly for this Perspective the relationship between enzyme activity and electrochemical potential may then be resolved with unprecedented resolution simply by measuring the catalytic current as a function of the potential applied to the electrode. The technical and conceptual considerations justifying this statement are detailed in a number of articles. ${ }^{11,14} \mathrm{~A}$ key point to stress here is that protein diffusion, much slower than events intrinsic to the catalytic cycle of an enzyme, is minimised if not excluded as a rate-limiting contribution to voltammetry when the protein is adsorbed on the electrode. The presence of non-rate limiting interfacial electron transfer can be confirmed experimentally and there are various approaches to ensure non-rate limiting transport of substrate(s) to the enzyme film such that the catalytic currents reflect the rates of events intrinsic to the catalytic mechanism of the enzyme.

Activity-potential relationships measured by PFE during steady-state nitrate reduction by NapAB purified from P. pantotrophus are illustrated in Fig. $2 .{ }^{15}$ These relationships, measured at $\mathrm{pH} 6$ and $20^{\circ} \mathrm{C}$, raise several questions. Why does the catalytic rate display a bell-shaped dependence on electrochemical potential? Why are appreciable rates of nitrate reduction only detected over limited windows of electrochemical potential? Why does nitrate concentration impact on the relationship in the way it does? How do the relationships respond to change of temperature and $\mathrm{pH}$ or the introduction of other molecules? These questions can be addressed from various perspectives, for example, by considering structural features of the enzyme or its cellular function. They can also be formulated more generally to ask whether the relationship between activity and electrochemical potential has evolved via the structure and mechanism of the enzyme to allow the enzyme to contribute most effectively to cellular metabolism.

$\dagger$ We use the term substrate to indicate a species transformed into product(s) by an enzyme rather than a solid material onto which other molecules are deposited.
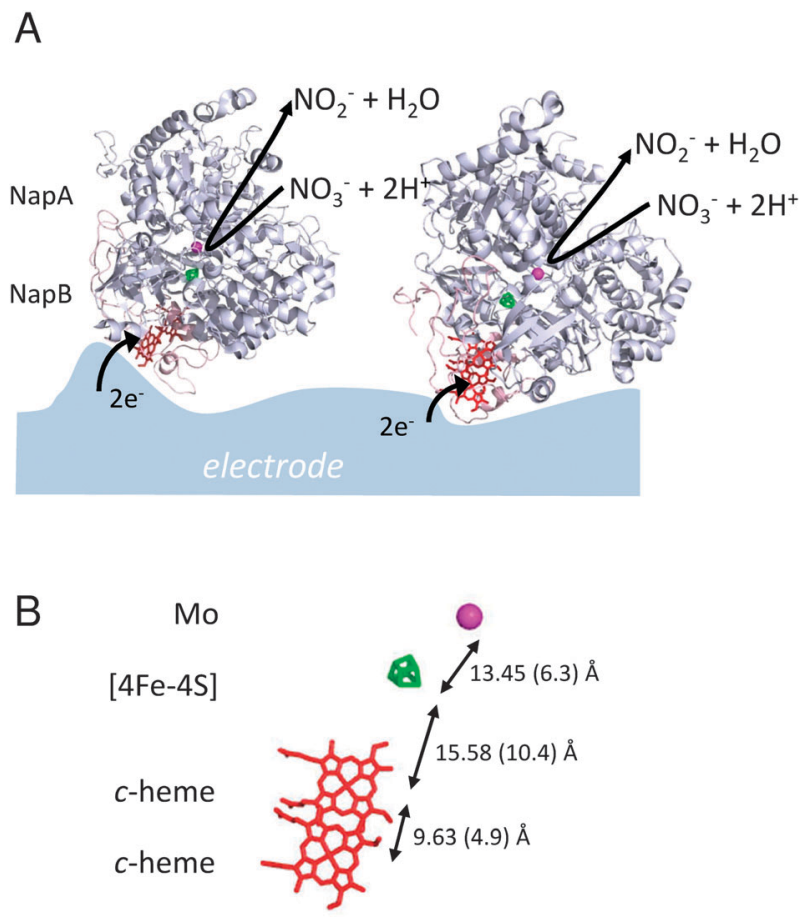

Fig. 1 Protein Film Electrochemistry and NapAB Nitrate Reductase. (A) Schematic of a sub-monolayer film of NapAB nitrate reductase adsorbed in an electrocatalytically active form as may be present during protein film electrochemistry. The Mo (purple) and $[4 \mathrm{Fe}-4 \mathrm{~S}]$ cluster (green) in NapA and the two heme groups (red) in NapB are indicated. (B) The arrangement of redox cofactors in NapAB indicating the centre-to-centre distances (edge-to-edge distances in brackets). The structure of NapAB is that from R. sphaeroides (PDB accession code 1OGY) rendered with PyMol.

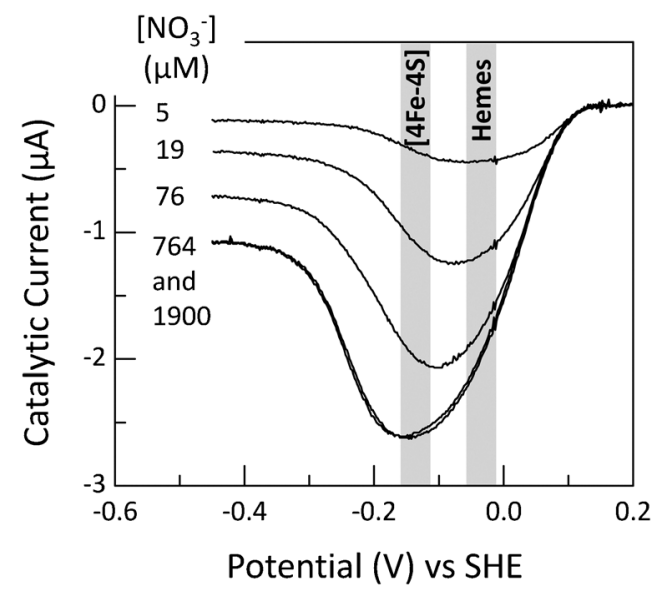

Fig. 2 Activity-potential relationships for P. pantotrophus NapAB resolved by PFE at $\mathrm{pH} 6,20^{\circ} \mathrm{C}$. The shaded bars indicate where redox transformation of the NapA $[4 \mathrm{Fe}-4 \mathrm{~S}]^{2+/ 1+}$ cluster and NapB hemes occur with a $40 \mathrm{mV}$ spread reflecting the likely uncertainty in the relevant reduction potentials.

Whichever perspective is of particular interest it is apparent that insights will only arise when the information afforded by PFE is integrated with that from other studies. Thus, we take a moment here to consider the PFE of NapAB in the context of results from other biochemical and physiological experiments. 
P. pantotrophus NapAB is representative of a large family of heterodimeric nitrate reductases composed of the two subunits, NapA and NapB, for which a molecular description is provided by a crystal structure of the NapAB from Rhodobacter sphaeroides, Fig. $1 .{ }^{16}$ The site of nitrate reduction is a Mo-containing cofactor coordinated by NapA. Nitrate binds to Mo(Iv) such that subsequent oxo-transfer produces nitrite and a $\mathrm{Mo}(\mathrm{vI})=\mathrm{O}$ containing cofactor. Reduction of the $\mathrm{Mo}(\mathrm{vI})=\mathrm{O}$ species coupled to protonation and loss of water returns the Mo(Iv) state to complete the catalytic cycle that achieves the net transformation: $\mathrm{NO}_{3}^{-}+2 \mathrm{e}^{-}+2 \mathrm{H}^{+} \rightarrow$ $\mathrm{NO}_{2}{ }^{-}+\mathrm{H}_{2} \mathrm{O}$. The structure of NapAB shows that the catalytically essential Mo ion is not located on the protein surface where it would be most readily accessible to nitrate and reductants, Fig. 1. Instead the Mo is surrounded by polypeptide such that two additional features of the protein structure are key for catalytic nitrate reduction. The first is a funnel extending $c a .20 \AA$ from the Mo through the polypeptide to the surface of NapA that allows exchange of nitrate, nitrite and water with bulk solution, Fig. 1. The second is a chain of redox cofactors, comprised of an iron-sulphur cluster and two heme groups, extending from the Mo to the surface of NapB, Fig. 1 and 3. Within this chain the neighbouring cofactors are separated by less than the $14 \AA$ proposed as the upper limit to sustain physiologically relevant rates of long-range electron transfer. ${ }^{17}$ Consequently the Mo ion, which would otherwise be insulated against facile electron exchange with anything except reductants that are small enough to diffuse directly into the active site, is able to exchange electrons with macroscopic redox partners via the surface exposed hemes in NapB. In cells of $P$. pantotrophus the macroscopic redox partner is the tetra-heme cytochrome NapC, Fig. 4, but in the PFE experiment it is the electrode.

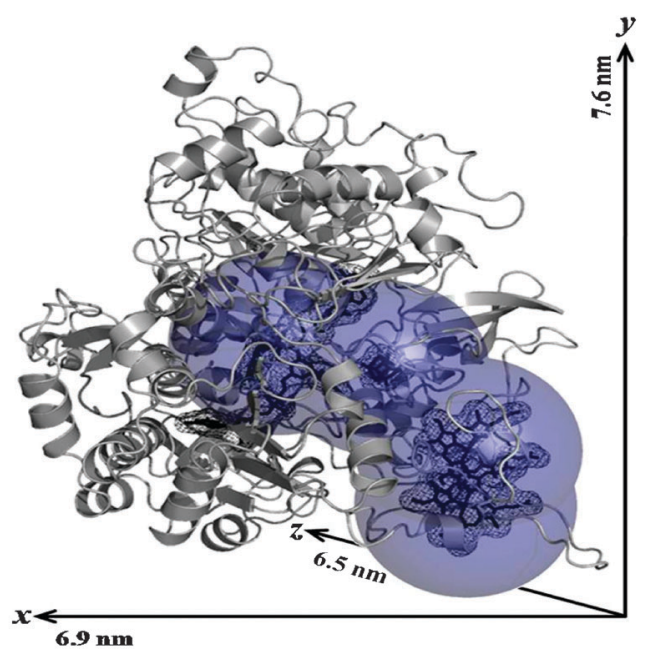

Fig. 3 The structure of NapAB highlighting the close proximity and 'wire-like' internal network of adjacent redox cofactors. A blue sphere of radius $14 \AA$ is positioned at the centre of each cofactor to represent the maximum distance an electron is likely to traverse at rates sufficient to support nitrate reduction at the experimentally observed rate of $c a .100$ nitrate molecules reduced per second. The structure of NapAB is that from $R$. sphaeroides (PDB accession code 1OGY) rendered with PyMol.

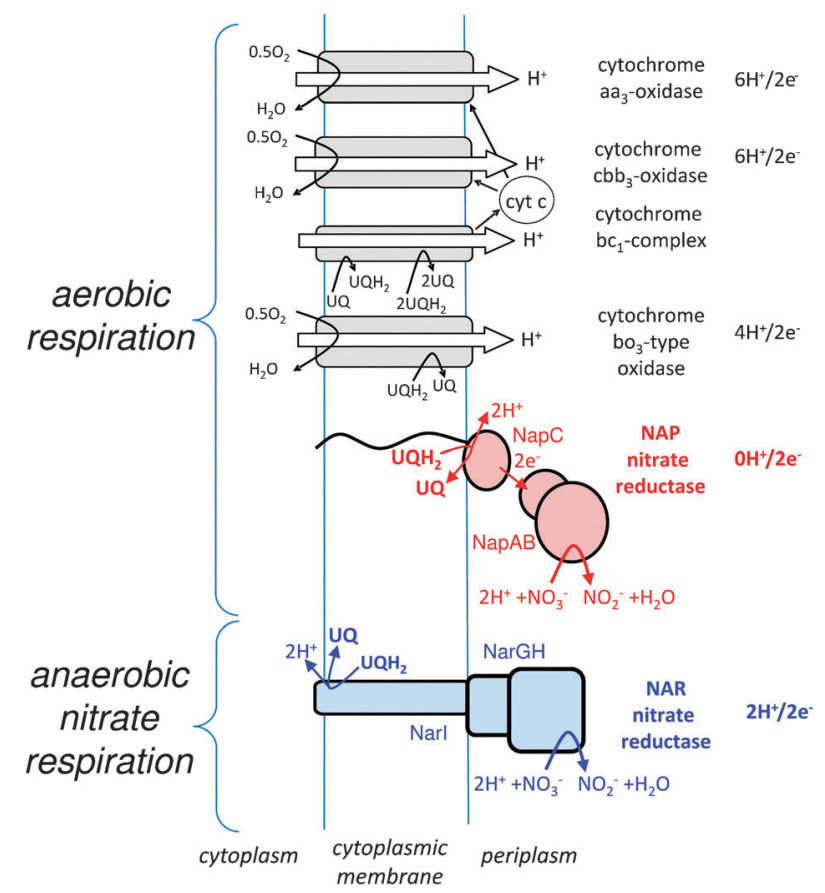

Fig. 4 Enzymes supporting respiratory electron transfer in $P$. pantotrophus. The contribution of each enzyme to maintaining the transmembrane proton gradient is indicated on the right of the figure.

From the discussion above we would anticipate that the electrode will functionally mimic the role of NapC in delivering electrons to NapAB. Thus, the catalytic mechanism and kinetics seen in PFE are expected to correlate with those displayed by the enzyme in its cellular context. Absolute rates of NapAB nitrate reduction, i.e., the number of molecules of nitrate reduced per NapAB molecule per second, are not available from PFE experiments at present because the population of electroactive enzyme molecules is too small to be quantified by detectable signals in the absence of substrate. ${ }^{15}$ However, variation of the catalytic rate with substrate concentration, and indeed other parameters, is readily defined by PFE and may be compared to the behaviour measured by other methods. The rate of an enzyme catalysed reaction is generally expected to increase and approach a limiting, maximal velocity $\left(V_{\max }\right)$ as substrate concentration $([\mathrm{S}])$ increases as is the case for NapAB nitrate reduction, e.g., Fig. 2. This behaviour is encapsulated in the Michaelis-Menten equation, rate $=V_{\max }[\mathrm{S}] /\left([\mathrm{S}]+K_{\mathrm{M}}\right)$, where $K_{\mathrm{M}}$ and $V_{\max }$ are characteristic of a given enzyme and its environment. PFE allows values of $K_{\mathrm{M}}$ and the maximum catalytic current $\left(i_{\max } \equiv V_{\max }\right)$ of NapAB to be reported as a function of electrochemical potential and the former ranges from $c a .5$ to $60 \mu \mathrm{M}$ with a non-linear dependence on both the electrochemical potential and the maximum catalytic current at $\mathrm{pH} 6$ and $20^{\circ} \mathrm{C}$, Fig. 5 .

To describe catalysis in the cellular context the MichaelisMenten equation is written with $K_{\mathrm{M}}$ replaced by the Monod constant, $K_{\mathrm{S}}$, to reflect the impact cellular structure and transport mechanisms may have on catalysis by the enzyme of interest. For NapAB we do not expect there to be significant perturbation of $K_{\mathrm{S}}$ from $K_{\mathrm{M}}$ since the enzyme is present in the periplasm where there should be minimal restrictions to 


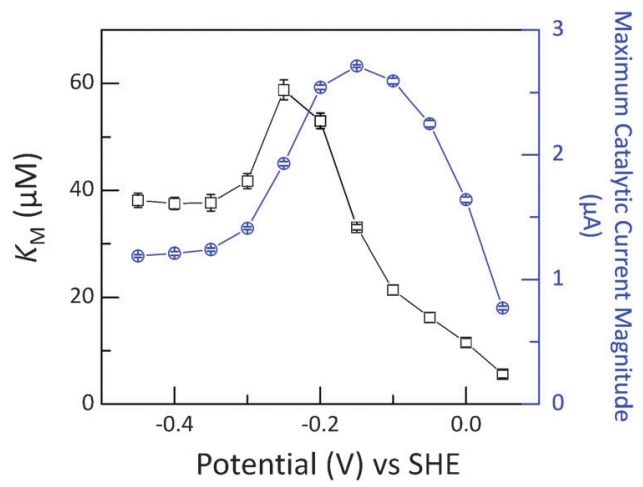

Fig. 5 Variation of $K_{\mathrm{M}}$ (black squares) and $i_{\max }$ (blue circles) with electrochemical potential for NapAB nitrate reduction at $\mathrm{pH} 6,20^{\circ} \mathrm{C}$.

nitrate/nitrite exchange with the extra-cellular medium where nitrate concentration can be measured to define $K_{\mathrm{S}}$. Indeed, NapAB nitrate reduction in $P$. pantotrophus is described by a $K_{\mathrm{S}}<15 \mu \mathrm{M}$ that is in good agreement with the $K_{\mathrm{M}}$ values from PFE. ${ }^{15}$ This supports the prediction that NapAB has a similar catalytic behaviour in cells of $P$. pantotrophus as in the PFE experiment. However, exactly how $K_{\mathrm{S}}$ should be related to the values of $K_{\mathrm{M}}$ defined by PFE is unclear as the electrochemical potential experienced by NapAB in the cellular experiment is not known - a point we return to later in the discussion.

In the foregoing discussion we have assumed that the structure of NapAB resolved in the crystalline state is that adopted by the enzyme when it is adsorbed on an electrode. Certainly scanning probe microscopies have provided evidence that supports protein adsorption with retention of the dimensions resolved by structural methods. ${ }^{18}$ However, for most enzymes studied by PFE there is little direct information available on the molecular structures or orientations adopted by the adsorbed proteins. For favourable combinations of electrode material and redox cofactor it is possible to use spectroscopy to correlate properties of the adsorbed proteins with the structural details resolved by X-ray diffraction and NMR methods e.g. ref. 19 and 20. However, it is more generally the case that comparison of enzyme activity resolved by PFE to that displayed by solutions of the purified enzyme is invaluable.

Catalysis by purified redox enzymes is typically assayed by electronic absorbance spectroscopy. The activity of interest is coupled to oxidation (or reduction) of a redox dye that is present at sufficiently high concentration not to limit the rate of the reaction. A change of absorbance due to the redox transformation of the dye then reports on the rate of the activity of interest. With a few notable exceptions the change of electrochemical potential implicit in these measurements is largely ignored so that single values of $K_{\mathrm{M}}$ and $V_{\max }$ are reported for a given set of conditions. $^{15,21,22}$ Assays of $P$. pantotrophus NapAB employing methyl viologen as the redox dye yield $K_{\mathrm{M}}$ values on the order of $150 \mu \mathrm{M}$ and so somewhat larger than those from PFE. This may reflect the ability of the dyes, or the reductants such as dithionite or $\mathrm{Zn}$ present in these assays, to enter the channel leading to the active site and impede substrate access. ${ }^{23,24}$ Alternatively, the protein:electrode interface may impact on catalysis in a manner that cannot be achieved in a dye based assay, for example, by providing hydrophobic and/or electrostatic interactions that may mimic those found at the interface of a protein:protein complex that is productive in intermolecular electron exchange. Significantly, the variation of $K_{\mathrm{M}}$ or $i_{\max }\left(V_{\max }\right)$ induced by change of $\mathrm{pH}$ or the introduction of an enzyme inhibitor is generally in good agreement for both solution assays and PFE. ${ }^{15,25-27}$ This supports adsorbed and solution states of NapAB displaying very similar catalytic behaviour even if there are differences in the exact values assigned to kinetic constants.

A discussion similar to that presented here for NapAB, where the description of activity resolved by PFE is in line with the properties resolved by other methods, can be prepared for many other enzymes. Thus, as we turn to address the implications and origins of the activity-potential relationship we will move forward with the premise that (a) the structural details provided by crystallographic and solution methods are relevant to describing the structure studied during PFE and (b) the activities defined by PFE are at least no worse than those from classical homogeneous assays of purified enzymes when it comes to considering the properties of these enzymes within living cells.

\section{Electrochemical potential as a determinant of electron flux through respiratory quinol- dehydrogenases - a mechanism for exerting metabolic control over redox enzyme activity}

The system comprised of NapAB together with NapC is one of many that serve to impart respiratory flexibility on Paracoccus species. ${ }^{28}$ This flexibility allows colonisation of diverse and changing environments since it provides multiple ways to transfer energy from catabolic events to the energy demanding anabolic processes that result in the production of new biomass. Key to this energy transfer is the formation of ATP which occurs as a direct consequence of the transmembrane proton gradient maintained by the activities of respiratory enzymes that redox cycle the quinone/quinol-pool, e.g., Fig. 4. Quinone (Q) is a small freely diffusible molecule, entrapped in the cytoplasmic membrane, which is reduced to quinol $\left(\mathrm{QH}_{2}\right)$ in a two-electron process coupled to catabolic events involving oxidation of a wide range of organic and inorganic molecules. $\mathrm{QH}_{2}$-dehydrogenases such as NapC then allow $\mathrm{QH}_{2}$ oxidation to be coupled to the reduction of terminal electron acceptors in processes that serve to recycle the Q-pool and that may contribute to the conservation of electrical energy as a trans-membrane proton gradient to drive ATP synthesis.

In Paracoccus it is redox cycling of ubiquinone (UQ) and ubiquinol $\left(\mathrm{UQH}_{2}\right)\left(E_{\mathrm{m}, 7} \approx+0.08 \mathrm{~V}\right)$ that links catabolic events to the reduction of terminal electron acceptors. ${ }^{28}$ When the NapABC system is present, during aerobic respiration where $\mathrm{O}_{2}$ is the terminal electron acceptor, so are two additional routes for $\mathrm{QH}_{2}$ oxidation, namely, a cytochrome $b o_{3}$ quinol-oxidase and the cytochrome $b c_{1}$-complex that delivers electrons to cytochrome $a a_{3^{-}}$and $c b b_{3}$-type oxidases via cytochrome $c$, Fig. 4. These oxidases reduce $\mathrm{O}_{2}$ to water and 
from a thermodynamic standpoint their activities would seem to offer the opportunity to harness more energy in the form of a transmembrane proton gradient than is possible from $\mathrm{QH}_{2}$-dependent nitrate reduction $\left(E_{\mathrm{m}, 7}\left(\mathrm{O}_{2} / \mathrm{H}_{2} \mathrm{O}\right) \approx+0.8 \mathrm{~V}\right.$, $E_{\mathrm{m}, 7}$ (nitrate/nitrite) $\left.\approx+0.4 \mathrm{~V}\right)$. Consequently, the presence of an active nitrate reductase alongside multiple oxidases during aerobic respiration has been a puzzle to microbiologists.

To gain insight into why NapABC may be present alongside these cytochrome oxidases we have considered the possible flux of electrons through each enzyme during growth of Paracoccus. This flux will reflect two factors. The total amount of enzyme present in a catalytically competent state, defined by mechanisms of genetic control and post-translational modification, and the activity of this enzyme, defined by its biochemistry. Both genetic and biochemical studies have provided evidence that the cytochrome $b o_{3}$ quinol-oxidase has a cellular role that is distinct from that of the cytochrome $b c_{1}$-dependent oxidases. ${ }^{29,30}$ The $b c_{1}$-complex, cytochrome $c$ and the $a a_{3}$ - and $c b b_{3}$-type oxidases are always present when $\mathrm{O}_{2}$ is available to support respiration. By contrast, synthesis of the cytochrome $b_{3} \mathrm{UQH}_{2}$-oxidase requires the presence of not only $\mathrm{O}_{2}$, but also more highly reduced molecules as organic substrates for the catabolic processes that feed electrons into the UQ-pool. Thus, cytochrome $b o_{3}$ is present during aerobic growth on the short-chain fatty acid butyrate for which full oxidation to $\mathrm{CO}_{2}$ may deliver up to twenty electrons into the UQ-pool and assimilation to the mean biomass composition $\left(\mathrm{CH}_{2} \mathrm{~N}_{0.25} \mathrm{O}_{0.5}\right)$ generates reductant. ${ }^{31}$ However, the presence of cytochrome $b_{3}$ is much lower during aerobic growth on malate (or succinate), for which full oxidation can supply only twelve (or fourteen) electrons and assimilation to the mean biomass composition consumes electrons. $^{29-31}$

We have found that the electron donating capacities of the catabolic substrates impact directly on the $\mathrm{UQ} / \mathrm{UQH}_{2}$ ratio in the membrane, i.e., the redox-poise of the UQ-pool. For $P$. pantotrophus HPLC analysis of the UQ-pool shows it to be substantially more reduced during aerobic growth on butyrate than during aerobic growth on succinate. This is particularly striking when it is noted that detectable activity from the cytochrome $b c_{1}$ dependent oxidases is observed when the fraction of $\mathrm{UQH}_{2}$ increases above $10 \%$ whereas a $\mathrm{UQH}_{2}$ content above $30 \%$ is required for similar activity of the cytochrome $b_{3} \mathrm{UQH}_{2}$-oxidase, Fig. $6 .{ }^{29}$ Thus, the mechanisms for biochemical (metabolic) and genetic (hierarchical) control of the activity of cytochrome $b_{3}$ reinforce each other. Growth on more highly reduced compounds not only triggers synthesis of cytochrome $b_{3}$ but also increases the fraction of $\mathrm{UQH}_{2}$ in the membrane such that it exceeds the threshold needed to detect significant activity from the cytochrome $b o_{3}$ that is present. Physiologically, it is notable that $P$. denitrificans exhibits marked di-auxic growth characteristics when grown on the mixture of succinate and butyrate with the former substrate consumed first and then butyrate being consumed with the concomitant increased synthesis of the NapABC system to facilitate redox balancing. ${ }^{32}$

How then do the catalytic properties of the NapABC system fit into this picture? We are not aware that NapABC activity

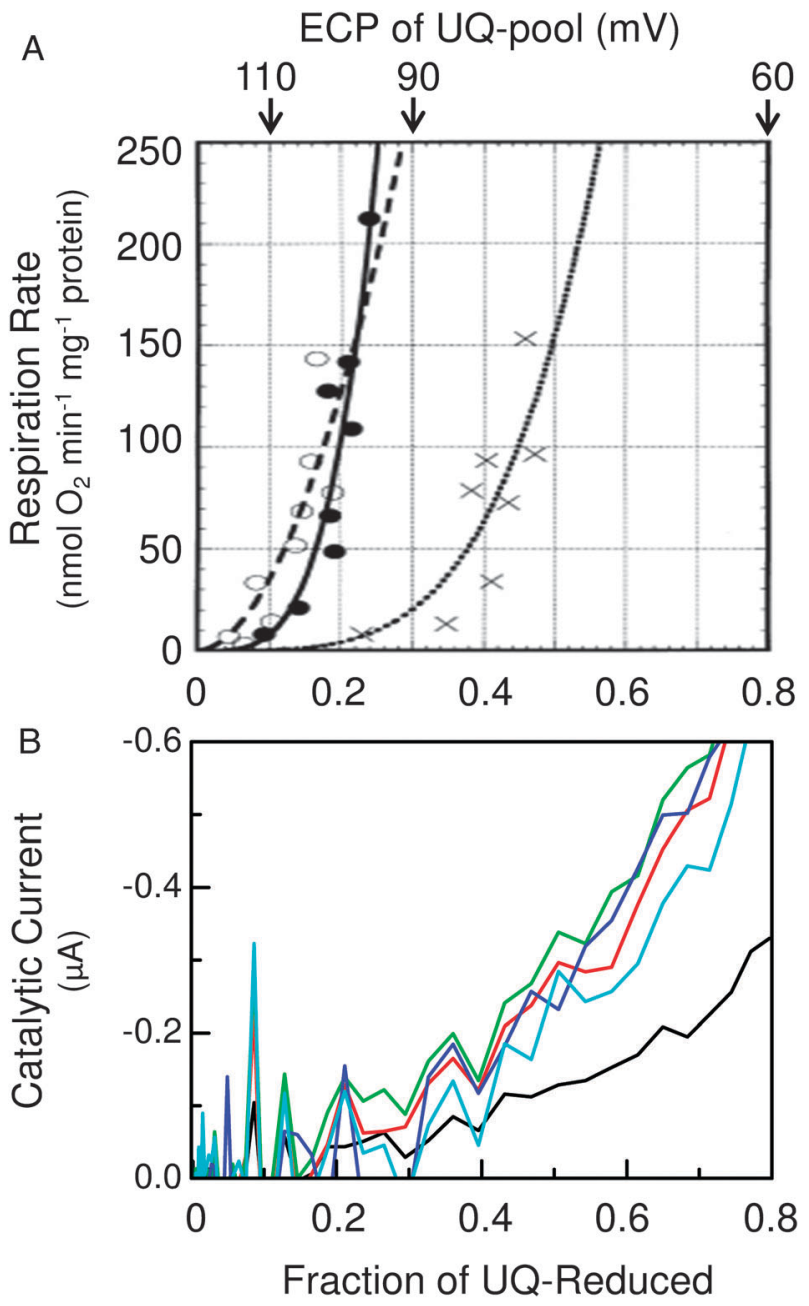

Fig. 6 The activity-potential relationships of the aerobic respiratory reductases of Paracoccus. (A) The cytochrome oxidases (redrawn from Otten et al. ${ }^{29}$ with permission). (B) NapAB from the data in Fig. 2, where the responses in 5, 19, 76, 764 and $1900 \mu \mathrm{M}$ are black, cyan, red, blue and green lines, respectively.

has been measured as a function of the $\mathrm{UQ} / \mathrm{UQH}_{2}$ ratio in membranes. However, the results from PFE should be relevant here. The $\mathrm{UQ} / \mathrm{UQH}_{2}$ ratio in the cytoplasmic membrane will give rise to an electrochemical potential, $E$, defined by the Nernst equation, $E=E_{\mathrm{m}}\left(\mathrm{UQ} / \mathrm{UQH}_{2}\right)+43 \times$ $10^{-6} T \ln \left([\mathrm{UQ}] /\left[\mathrm{UQH}_{2}\right]\right)$ where $T$ is the temperature. When the fraction of $\mathrm{UQH}_{2}$ in membranes of Paracoccus increases, for example from $30 \%$ to $80 \%$, the potential imposed by the UQ-pool is predicted to drop from ca. 0.09 to 0.06 V, Fig. 6 . PFE shows that the activity of NapAB increases significantly when the potential drops below $c a$. $+0.10 \mathrm{~V}$, Fig. 2, leading to prediction that in Paracoccus the NapABC system will be active only when growth is supported by molecules that feed more electrons into the UQ-pool than succinate. Indeed, plotting the data in Fig. 2 after using the Nernst equation to convert the electrochemical potential to the fraction of $\mathrm{UQH}_{2}$ shows that NapAB activity increases significantly as $\mathrm{UQH}_{2}$ rises above $30 \%$. This then ties in with the consequences of genetic regulation that produce maximum levels of NapAB during aerobic growth on butyrate. ${ }^{31-33}$ Thus, biochemical 
and genetic control of NapAB activity reinforce one another in a parallel scenario to that describing the activity of cytochrome $b o_{3}$. We note here that PFE predicts $K_{\mathrm{M}}$ values below $15 \mu \mathrm{M}$ for the electrochemical potentials that are likely to be experienced by NapAB in vivo, Fig. 5, and so in good agreement with the $K_{\mathrm{S}}$ value derived from cellular studies. ${ }^{15}$

The observations outlined have led us to propose that the electrochemical potentials over which the activities of $\mathrm{QH}_{2}$-dehydrogenases move between negligible and maximal values are tuned to reinforce their cellular function. ${ }^{15,34}$ To understand why Paracoccus increases the activities of cytochrome $b_{3}$ and NapABC in response to a lower redox poise of the UQ-pool we must consider the contribution of each $\mathrm{QH}_{2}$ oxidising system to conserving the energy of catabolism, Fig. 4. For each $\mathrm{UQH}_{2}$ oxidised by the two cytochrome $b c_{1}$ dependent cytochrome oxidases six protons are added to the transmembrane proton gradient. The activity of cytochrome $b o_{3}$ contributes four protons to this gradient for each $\mathrm{UQH}_{2}$ oxidised while NapABC contributes none. Thus, the activities of NapABC and cytochrome $b o_{3}$ appear designed to prevent the build up of an excessive transmembrane proton gradient when the fraction of $\mathrm{UQH}_{2}$ exceeds a certain level. Indeed, we anticipate that the activity of the cytochrome $b c_{1}$ dependent oxidases will drop above a certain ratio of $\mathrm{UQH}_{2}$ to UQ since both molecules are substrates for the enzyme. ${ }^{35}$ These combined effects will increase electron flux through the cytochrome $b c_{1}$ independent respiratory reductases such that excess electrons are vented from the UQ-pool without contributing to the transmembrane proton gradient. This is consistent with a redox balancing system that operates to poise the aerobic respiratory electron transport system to maximise the rate of cellular growth.

We have seen that the activities of NapABC and cytochrome $\mathrm{bo}_{3}$ result in less complete coupling of energy transfer between catabolic and anabolic processes. Thus, our hypothesis is that the modulation of the activities of these enzymes imposed by the electrochemical potential of the UQ-pool complements genetic control to ensure that the energy released in catabolic processes does not go to waste unnecessarily. A number of studies have shown that growth yields (grams of cell produced per mole of substrate consumed) are lower than predicted from considering the thermodynamics of the catabolic and anabolic events such that the ability to waste energy is intrinsic to cellular life, e.g., ref. 36-38. However, growth yields have been found to vary in response to change of environment in a manner that suggests a key element of microbial respiration is the ability to spill, or dissipate, excess energy at a rate appropriate to the prevailing conditions. Thus, the tuning of $\mathrm{QH}_{2}$-dehydrogenase activities to allow their cellular activities to be modulated by a change of the electrochemical potential imposed by the redox-poise of the Q-pool may provide a rapid, first-line of response to environmental change.

PFE of additional enzymes provides further support for our hypothesis. The NarGHI system which couples $\mathrm{UQH}_{2}$ oxidation to nitrate reduction is essential to supporting anaerobic growth of Paracoccus using nitrate as its terminal respiratory electron acceptor. ${ }^{28}$ In contrast to the Nap system, the Nar system is expressed and active during anoxic, rather than oxic growth conditions ${ }^{31}$ and so does not have to compete with the oxidases for electrons from the quinol pool. NarGH activity appears at potentials $c a .0 .08 \mathrm{~V}$ more positive than required for NapAB activity ${ }^{39}$ such that as little as $1 \% \mathrm{UQH}_{2}$ in the membranes will drive nitrate reduction by NarGHI. NarGHI differs from NapABC in that it catalyses $\mathrm{UQH}_{2}$ oxidation and nitrate reduction on the opposite sides of the membrane, Fig. 4. Consequently, and unlike NapABC, NarGHI contributes to maintaining a transmembrane proton gradient. Thus, it makes sense that this energy-conserving nitrate reductase, like the cytochrome $b c_{1}$-dependent oxidases will have its activity-potential relationship tuned so that very few electrons need to accumulate in the UQ-pool before activity is switched on. The activities of the nitrate reductases and oxidases discussed above also nicely illustrate how the extent of energy conservation is determined not by the difference in reduction potentials of the donor/acceptor couples, or indeed the operational potential of the terminal reductase, but rather by the extent to which the enzyme allows electron transfer to be coupled to the generation of proton motive force.

Beyond Paracoccus, many microorganisms, including E. coli, synthesise multiple quinones. Synthesis of these quinones is regulated in response to growth conditions. Ubiquinone is predominant when succinate serves as electron and carbon source and $\mathrm{O}_{2}$ as respiratory electron acceptor. However, anaerobic growth leads to a predominance of menaquinones (MQ) that may mediate electron transfer from formate dehydrogenase to the nitrate or nitrite reductases. ${ }^{40}$ The reduction potential of $\mathrm{MQ} / \mathrm{MQH}_{2}\left(E_{\mathrm{m}, 7} \approx-0.07 \mathrm{~V}\right)$ is lower than that of $\mathrm{UQ} / \mathrm{UQH}_{2}$ so we anticipate that lower potentials will be required to see appreciable activities from the MQ-, than UQ-, dependent enzymes. Certainly, activity from the E. coli penta-heme nitrite reductase, $\mathrm{NrfA}$, a $\mathrm{MQH}_{2}$-dependent system is only detected below $c a .-0.07 \mathrm{~V} .^{41,42}$ In this light it is striking that potentials below $c a .-0.30 \mathrm{~V}$ are required to see any appreciable activity from the assimilatory nitrate reductase (Nas) of Synechococcus elongatus. ${ }^{34}$ These potentials are too low to be engaged by the $\mathrm{Q} / \mathrm{QH}_{2}$-pool. However, they are ideally poised to be engaged by the low potential ferredoxin redox partner that receives electrons from photosystem $\mathrm{I}^{43}$ Thus, it may be a general phenomenon that the activity-potential relationship of a redox enzyme is tuned to complement potentials imposed by the redox poise of the electron transfer partner and so facilitate cellular function.

That electrochemical potential, via the redox poise of the $\mathrm{Q} / \mathrm{QH}_{2}$ and $\mathrm{NAD}(\mathrm{P})^{+} / \mathrm{NAD}(\mathrm{P}) \mathrm{H}$-pools, contributes to metabolic regulation as we propose should perhaps not come as a surprise since its role in genetic regulation is wellestablished..$^{40,44,45}$ Testing our hypothesis requires that enzyme activities and electrochemical potentials are correlated in the cellular context. In the first instance, the activities of periplasmically facing enzymes such as NapAB will be most readily measured in chemostat cultures where the rates of substrate consumption and/or product formation can be determined by analysis of the extracellular medium. Rapid sampling of the culture followed by $\mathrm{Q} / \mathrm{QH}_{2}$ extraction and HPLC analysis provides one route to define the redox status of the Q-pool. Alternatively a Q-electrode allows for continuous monitoring of the $\mathrm{Q} / \mathrm{QH}_{2}$ redox poise through polarographic 
analysis of exogenously added ubiquinone-1 that equilibrates with the cellular Q-pool. ${ }^{46}$ There is clearly also scope for developing an in vivo reporter of the $\mathrm{Q} / \mathrm{QH}_{2}$-ratio analogous to the green fluorescent protein variants that report the redox poise of aqueous compartments. ${ }^{47}$

\section{The molecular basis of activity-potential relationships tuned to reinforce cellular function}

The proposal that the activity-potential relationships displayed by $\mathrm{QH}_{2}$-dehydrogenases, and perhaps all oxidoreductases, are tuned to reinforce cellular function implies these relationships are characteristic of a given enzyme and its environment. For the enzymes studied to date this is indeed the case. ${ }^{9-13}$ Multi-dimensional representations of activities as a function of electrochemical potential, $\mathrm{pH}$, temperature and the concentrations of both substrates and inhibitors/activators provide a 'fingerprint' of activity that is unique to each enzyme and that must originate in its structure. Conservative substitutions of single amino acids can redefine these fingerprints ${ }^{21,48}$ but to appreciate the multitude of ways in which this may occur requires an understanding of the parameters underpinning redox catalysis.

To account quantitatively for the activity-potential relationship requires that the catalytic mechanism and relevant rates are resolved across the potential domain. This is not immediately achieved by the descriptions of enzyme catalysis proposed by Michaelis and Menten. However, their approach is readily extended to include steps that describe redox events and so a dependence of the catalytic rate on electrochemical potential. ${ }^{12,39,49}$ In the simplest case the activity of a reductase would be expected to be negligible at more positive potentials since the fully oxidised enzyme lacks reducing equivalents that can be passed to substrate. Lowering the potential into a critical domain related to the reduction potentials of centres in that enzyme will significantly increase the population of reduced, catalytically-competent enzyme. Thus, reductase activity is expected to increase in a sigmoidal fashion reflecting a Nernstian increase in the population of reduced and active enzyme.

In reality many factors combine to determine the precise range of potential over which activity varies between negligible and maximal values. This is readily illustrated by considering a catalytic cycle for substrate reduction that is dependent on the presence of two redox centres, Scheme 1. One of these centres is associated with the active site and participates directly in substrate reduction while the second centre relays the electrons required for catalysis to the active site from the physiological redox partner or electrode. Both centres undergo singleelectron redox transformations and the substrate is reduced by one electron to form product. Steady-state analysis of Scheme 1 relates activity to potential through an equation that includes the reduction potentials of the relay and active site redox centres in addition to the indicated rate constants. ${ }^{12,49}$ While all combinations of these parameters produce a sigmoidal dependence of activity on potential the details of the relationship vary, e.g., Fig. 7A and B.

The activity-potential relationships in Fig. 7 differ only in the values of the rate constant $\left(k_{\text {intra }}\right)$ for intra-molecular

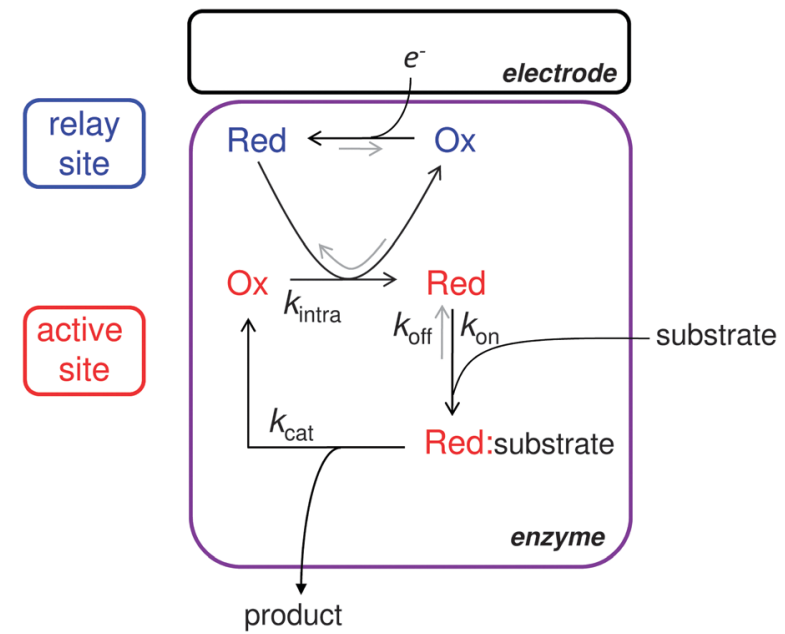

Scheme 1 A mechanism for electrocatalytic reduction of a singleelectron substrate by an enzyme with redox centres involved in substrate reduction within the enzyme active site and electron relay. Rate constants appearing in the steady-state expression for the activity-potential profile arising from this mechanism are indicated and $K_{\mathrm{M}}=\left(k_{\text {off }}+k_{\text {cat }}\right) / k_{\text {on }}$.
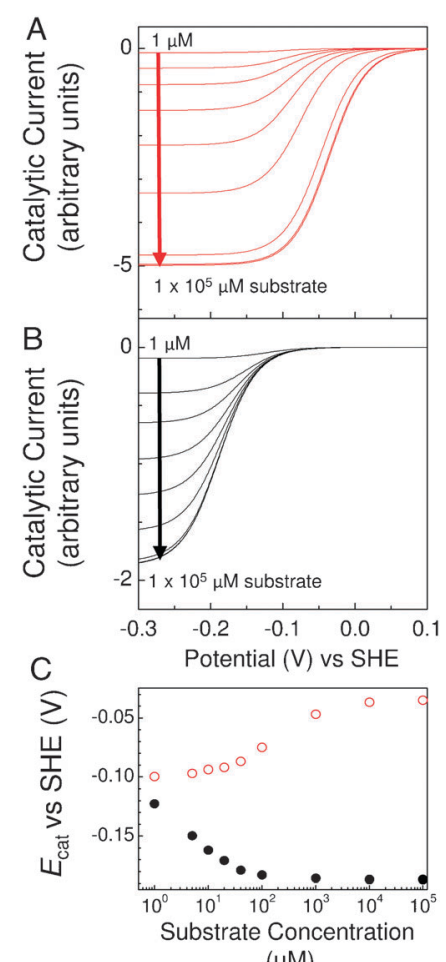

$(\mu \mathrm{M})$

Fig. 7 Steady-state activity-potential relationships predicted for Scheme 1. The parameters used were $k_{\text {intra }}=3000 \mathrm{~s}^{-1}$ (A) and $3 \mathrm{~s}^{-1}$ (B) with in both cases $E_{\mathrm{m}}$ (relay) $=-0.2 \mathrm{~V}, E_{\mathrm{m}}$ (active site) $=-0.1 \mathrm{~V}$, $K_{\mathrm{M}}=5 \times 10^{-5} \mathrm{M}, k_{\mathrm{cat}}=5 \mathrm{~s}^{-1}$. The relationships are illustrated for 1 , $5,10,20,40,100,1000,10000$ and $100000 \mu \mathrm{M}$ substrate as indicated. (C) The dependence of $E_{\text {cat }}$ on substrate concentration where $E_{\text {cat }}$ is the potential of steepest gradient in the activity-potential relationship, red circles for the data in A and black circles for data in B.

electron transfer between the relay and active site redox centre; $k_{\text {intra }} \gg k_{\text {cat }}$ and $k_{\text {intra }} \approx k_{\text {cat }}$ in panels $\mathrm{A}$ and $\mathrm{B}$ respectively. From this it is clear that both the ratio of $k_{\text {intra }}$ to $k_{\text {cat }}$ and 
substrate concentration may impact on the potential window over which the activity varies from a negligible to maximal value. This potential window can be quantified by the potential of steepest gradient, $E_{\text {cat }}$, in the activity-potential relationship, Fig. 7C. At $1 \mu \mathrm{M}$ substrate for both $k_{\text {intra }} \gg k_{\text {cat }}$ and $k_{\text {intra }} \approx$ $k_{\text {cat }}$ the value of $E_{\text {cat }}$ lies close to $-0.1 \mathrm{~V}$, i.e., the reduction potential of the active site. Here the activity-potential relationship approximates to a Nernstian description of the percentage of enzyme with the reduced active site that is capable of substrate reduction. For the case where $k_{\text {intra }} \gg k_{\text {cat }}$, the value of $E_{\text {cat }}$ is displaced to increasingly positive potential as the substrate concentration is raised, Fig. 7A and C. This reflects substrate binding to the reduced form of the active site raising its apparent reduction potential in a manner analogous to the familiar shift of $\sim 60 \mathrm{mV}$ per $\mathrm{pH}$ unit characteristic of singleelectron transfer coupled to binding of one proton. For all substrate concentrations when $k_{\text {intra }} \gg k_{\text {cat }}$ the value of $E_{\text {cat }}$ reflects the apparent reduction potential of the active site and there is negligible impact of the electron relay site on the activity-potential relationship. This is in contrast to the case when $k_{\text {intra }} \approx k_{\text {cat }}$. Now, the value of $E_{\text {cat }}$ tends towards the reduction potential of the electron relay site $(-0.2 \mathrm{~V})$ as substrate concentration increases and the rate-limiting events of catalysis become increasingly associated with intramolecular electron transfer from the relay to active site, Fig. 7B and C.

These examples illustrate how activity-potential relationships reflect a combination of thermodynamic and kinetic parameters describing the catalytic cycle. Each of these parameters is defined by multiple structural features. Interactions with solvent water, local hydrogen bonds, longer range chargecharge or charge-dipole interactions and conformational change triggered by the reaction contribute to defining reduction potentials. The difference in reduction potential, reorganisation energy, separation and the nature of the intervening medium defines rates of intramolecular electron transfer while substrate binding and transformation will be defined, respectively, by rate constants reflecting movement of the substrate/product to the active site and the energetics of the pathway linking substrate(s) to product(s). These parameters are clearly inter-related such that the activity-potential relationships are a rich, and as yet relatively untapped, source of information on the relationship between the structure and functional properties of redox enzymes that are ripe for addressing by both experimental and computational approaches.

Returning to NapAB in this light, it is apparent that Scheme 1 is unable to account for the peaked activity-potential relationship displayed during nitrate reduction, Fig. 2. While NapAB may not experience potentials sufficiently negative to engage the attenuated rate in vivo, Fig. 6 , it is clearly of interest to account fully for the activity resolved by PFE. Understanding the molecular basis of NapAB activity may also inform the studies of other enzymes that display peaks of activity in the potential domain as described by Léger and Bertrand, ${ }^{13}$ Elliott et al. ${ }^{50}$ and references therein. The pentaheme nitrite reductase NrfA, synthesized during anaerobic metabolism of nitrate and nitrite under electron-acceptor limited conditions, is one of these enzymes. ${ }^{41,42,51}$ During nitrite reduction at low substrate concentrations $(1.7 \mu \mathrm{M})$

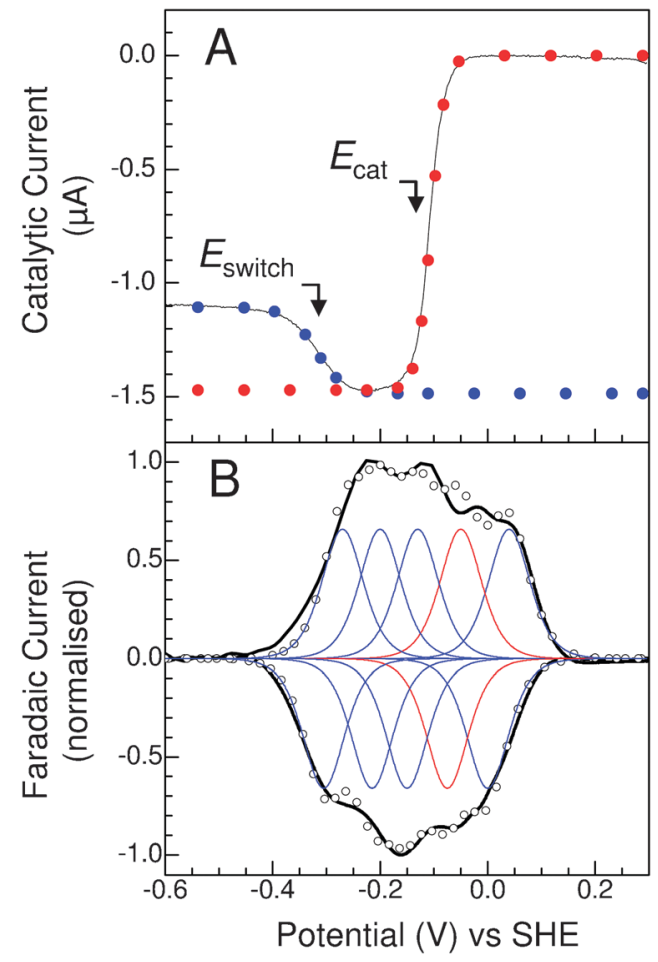

Fig. 8 PFE of E. coli NrfA nitrite reductase. (A) The steady-state activity-potential relationship for NrfA in $1.7 \mu \mathrm{M}$ nitrite. The circles show an $n=1$ Nernstian response centred on $-0.1 \mathrm{~V}$ (red) and $-0.32 \mathrm{~V}$ (blue). (B) Spectroelectrochemistry of NrfA in the absence of nitrite showing the contribution of high-spin (red) and low-spin (blue) hemes to the voltammetric response (black). The circles represent the sum of the individual heme components. Data collected in $20 \mathrm{mM}$ Hepes, $2 \mathrm{mM} \mathrm{CaCl}_{2}, \mathrm{pH} 7,20{ }^{\circ} \mathrm{C}$.

the activity-potential relationship displayed by NrfA contains a plateau of maximal activity such that the relationship can be described by two Nernstian responses; one, centred on $E_{\text {cat }}$, describes the onset of activity and the second, centred on $E_{\text {switch }}$, describes the attenuation of activity at increasingly negative potentials, Fig. 8A. A nitrite concentration of $1.7 \mu \mathrm{M}$ is well below the $K_{\mathrm{M}}$ values for all potentials where NrfA has significant nitrite reductase activity so that the reduction potentials of the enzyme cofactors may inform on the redox transformations that modulate the activity. ${ }^{20}$ The value of $E_{\text {cat }}$ correlates with $E_{\mathrm{m}}$ of the active site heme while $E_{\text {switch }}$ has a value close to the reduction potential of the lowest potential relay, Fig. 8B. Thus, for NrfA it appears that the attenuation of activity at low potentials reflects formal reduction of a site positioned some distance from the active site. ${ }^{52}$

One mechanism by which a change of oxidation state could change the rate of a reaction is through a change in the products of reduction. Multiple products have been reported for reduction of nitrite by various heme proteins. ${ }^{53-55}$ To assess if this is the case for NrfA the consumption of electrons and nitrite was correlated for films poised at -0.15 and $-0.40 \mathrm{~V}$ where activity is maximal and attenuated, respectively, Table 1. At both potentials six electrons were consumed for every nitrite reduced suggesting ammonium as the product of nitrite reduction. This was confirmed by quantifying the ammonium produced by films poised at -0.15 and $-0.40 \mathrm{~V}$, 
Table 1 Resolution of the product of NrfA nitrite reduction across the electrochemical potential domain. Films poised at the potential indicated in $50 \mathrm{mM}$ phosphate, $\mathrm{pH} 7$ at $20^{\circ} \mathrm{C}$

\begin{tabular}{|c|c|c|c|c|c|c|}
\hline $\begin{array}{l}\text { Potential/ } \\
\text { V vs. } \\
\text { SHE }\end{array}$ & $\begin{array}{l}\text { Electrons } \\
\text { consumed }^{a} \\
\text { (nmoles) }\end{array}$ & $\begin{array}{l}\text { Nitrite } \\
\text { consumed } \\
\text { (nmoles) }\end{array}$ & $\begin{array}{l}\text { Ratio of electrons } \\
\text { consumed/nitrite } \\
\text { consumed }\end{array}$ & $\begin{array}{l}\text { Electrons } \\
\text { consumed } \\
\text { (nmoles) }\end{array}$ & $\begin{array}{l}\text { Ammonia } \\
\text { produced }^{c} \\
\text { (nmoles) }\end{array}$ & $\begin{array}{l}\text { Ratio of electrons } \\
\text { consumed/ammonia } \\
\text { produced }\end{array}$ \\
\hline \multirow[t]{5}{*}{$-0.15 \mathrm{~V}$} & 24.1 & 3.78 & 6.38 & 75.74 & 14.1 & 5.37 \\
\hline & 136.2 & 29.12 & 4.68 & 28.69 & 4.8 & 5.98 \\
\hline & 58.2 & 9.00 & 6.47 & 12.21 & 3.7 & 3.30 \\
\hline & & & & 26.93 & 3.0 & 8.98 \\
\hline & & & Average $5.84 \pm 1.5$ & & & Average $5.91 \pm 3.1$ \\
\hline \multirow[t]{5}{*}{$-0.40 \mathrm{~V}$} & 321.7 & 59.50 & 5.41 & 36.52 & 6.3 & 5.80 \\
\hline & 259.7 & 40.26 & 6.45 & 9.47 & 2.3 & 4.12 \\
\hline & 339.5 & 47.90 & 7.09 & 43.36 & 4.3 & 10.08 \\
\hline & & & & 25.23 & 7.0 & 3.60 \\
\hline & & & Average $6.32 \pm 0.9$ & & & Average $5.90 \pm 4.2$ \\
\hline
\end{tabular}

${ }^{a}$ Measured by chronocoulometry. ${ }^{b}$ The difference between initial and final concentrations in the electrochemical cell as determined colorimetrically by the Griess reaction. ${ }^{78-80 c}$ The difference between initial and final concentrations in the electrochemical cell as determined by quantification of the product through its stoichiometric reaction with $o$-phthalaldehyde to produce a fluorescent isoindole. ${ }^{81-83}$

Table 1, such that the difference between the maximal and attenuated rates of NrfA nitrite reduction must be attributed to a change in the rate-defining event associated with nitrite ammonification.

Given that NapAB reduces nitrate to nitrite by oxo-transfer to $\mathrm{Mo}(\mathrm{IV})$ it is unlikely that the product of the reaction changes in response to a change of electrochemical potential. Modulation of the catalytic rate by a change in the orientation of the enzyme on the electrode or differential flux through distinct routes for electron transfer to the active site cannot be ruled out. $^{56}$ The surface of the enzyme would be likely to play an important role in defining the activity-potential profile in such cases. However, very similar activity-potential profiles are displayed by enzymes of the same family, including NapAB, that have high homology around their active sites and redox cofactors but little homology on their surfaces. ${ }^{15,57,58}$ Thus, we consider it more likely that the attenuated rate of NapAB nitrate reduction arises from a change of rate-defining event within the intrinsic mechanism of the enzyme. Unambiguous description of the NapAB activity-potential relationship into two Nernstian components is prevented by its peaked nature. Comparing the relationship to the reduction potentials of the $[4 \mathrm{Fe}-4 \mathrm{~S}]^{2+/ 1+}$ cluster and hemes of NapAB suggests that the oxidation state of the former centre may be responsible for defining the catalytic rate, Fig. 2. However, in the absence of information on the catalytically relevant reduction potentials of the $\mathrm{Mo}^{15,39,59}$ it cannot be ruled out that this behaviour arises from Mo-based redox chemistry in a situation analogous to that proposed for the active site redox chemistry of succinate dehydrogenase and NarGH. ${ }^{39,60}$

An opportunity to resolve contributions of the various cofactors to the activity-potential relationship is provided by the ability of $P$. pantotrophus to insert $\mathrm{W}$ into NapAB in place of Mo. ${ }^{61}$ Specific contributions made by $\mathrm{Mo}(\mathrm{W})$ to the activity-potential relationship may then be resolved by virtue of the systematic differences displayed by isostructural Mo/W complexes; namely, faster rates of oxo-transfer from substrate to W(IV) than Mo(IV) and a lower $E_{\mathrm{m}}$ for W than Mo for a given couple. ${ }^{62,63}$ NapAB substituted with W (W-NapAB) purifies in the same manner and has the same electrophoretic properties as the Mo containing enzyme indicating that there are minimal differences in the structure and charge of these enzymes. W-NapAB retains the peaked activity-potential relationship of Mo-NapAB but displays a higher ratio of maximal to attenuated activity, Fig. 9A and B. Differences in the activities of these enzymes are also evident in the $K_{\mathrm{M}}$ values of $19 \pm 5 \mu \mathrm{M}$ and $38 \pm 6 \mu \mathrm{M}$ at $-0.4 \mathrm{~V}$ for $\mathrm{W}$ - and Mo-NapAB, respectively, and of $6 \pm 3 \mu \mathrm{M}$ and $22 \pm 5 \mu \mathrm{M}$ at the peak potential for $\mathrm{W}$ - and Mo-NapAB, respectively. The slightly lower $K_{\mathrm{M}}$ values of the $\mathrm{W}$ - as compared to Mo-enzyme coincide with the relative behaviours of the W-/Mo-containing selenate- and trimethlyamine oxide reductases ${ }^{64,65}$ but is in contrast to the very similar $K_{\mathrm{M}}$ values displayed by the W- and Mo-containing forms of the membrane associated nitrate reductase of Pyrobaculum aerophilum. ${ }^{66}$

At low nitrate concentrations $E_{\text {cat }}$ is more negative for W- than Mo-NapAB, Fig. 9C. These are conditions where $E_{\text {cat }}$ is most likely to reflect reduction potentials of the active site and so the results are consistent with a contribution to $E_{\text {cat }}$ from the reduction potential of a $\mathrm{W}$ couple that is lower than its Mo equivalent. ${ }^{62,63,67}$ At higher nitrate concentrations the values of $E_{\text {cat }}$ converge, while there is negligible difference in

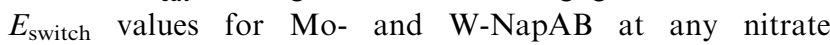
concentration, Fig. 9C. Thus, substituting W for Mo produces subtle changes in the activity-potential relationship without perturbing its defining characteristics. By contrast, single amino acid substitutions in the catalytic subunit of $R$. sphaeroides NapAB can significantly alter this relationship. ${ }^{21}$ Relative to NapAB the attenuation is much less pronounced for Q384N, M153A displays a boost rather than attenuation of activity while R392A produces only modest changes in the activity-potential relationship. The maximal activities of all three variants are comparable to that of the native enzyme but the $K_{\mathrm{M}}$ values are raised 4-, 10- and 200-fold in Q384N, M153A and R392A, respectively, demonstrating a compromised ability to bind, rather than reduce, nitrate. Q384 and M153 are positioned close to the Mo while the side chain of R392 is located ca. $9 \AA$ away, Fig. 10. Their substitution impacts on the reduction potentials of the $[4 \mathrm{Fe}-4 \mathrm{~S}]^{2+/ 1+}$ and heme cofactors and so presumably also on those of the Mo centre. Thus, rates of intramolecular electron transfer may also be altered. Consequently the properties of these variants reinforce the inter-related nature of the parameters 

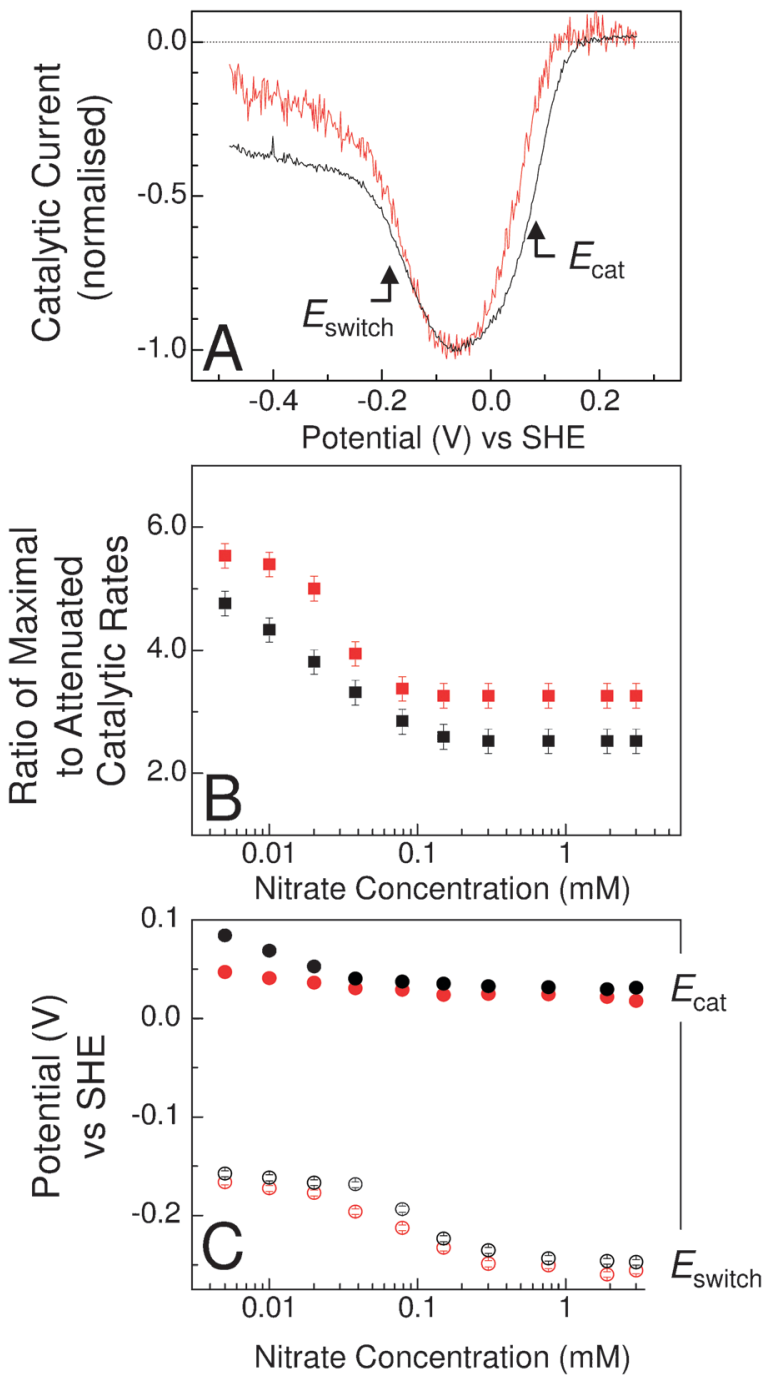

Fig. 9 Comparison of the activity-potential relationships displayed by NapAB (black) and W-substituted NapAB (red). (A) Activitypotential profiles for catalysis in $5 \mu \mathrm{M}$ nitrate, $\mathrm{pH} 6,20^{\circ} \mathrm{C}$ with $E_{\text {cat }}$ and $E_{\text {switch }}$ indicated for Mo-containing NapAB. (B) The ratio of maximal to attenuated activity as a function of nitrate concentration. (C) Variation of $E_{\text {cat }}$ and $E_{\text {switch }}$ with nitrate concentration.

underpinning the activity-potential relationships and the challenge that accounting for these relationships at the molecular level represents.

As yet there is no consensus on the molecular mechanism that gives rise to the activity-potential relationship displayed by NapAB. Details of the specific mechanisms that have been proposed can be found in a number of papers ${ }^{13,15,21,39}$ and we present the discussion above to stimulate further interest in accounting for activity-potential relationships at the molecular level. Experimental approaches that resolve enzyme states structuro-spectroscopically across the potential domain will be valuable. This may be achieved by optically transparent electrodes or opaque electrodes and vibrational spectroscopy, e.g., ref. 19, 20 and 68. However, there is also much scope for contributions from computational methods. The oxo-transfer chemistry of Mo (and W) has been extensively analysed by DFT, e.g., ref. 62, 63 and 69 and references therein. However,

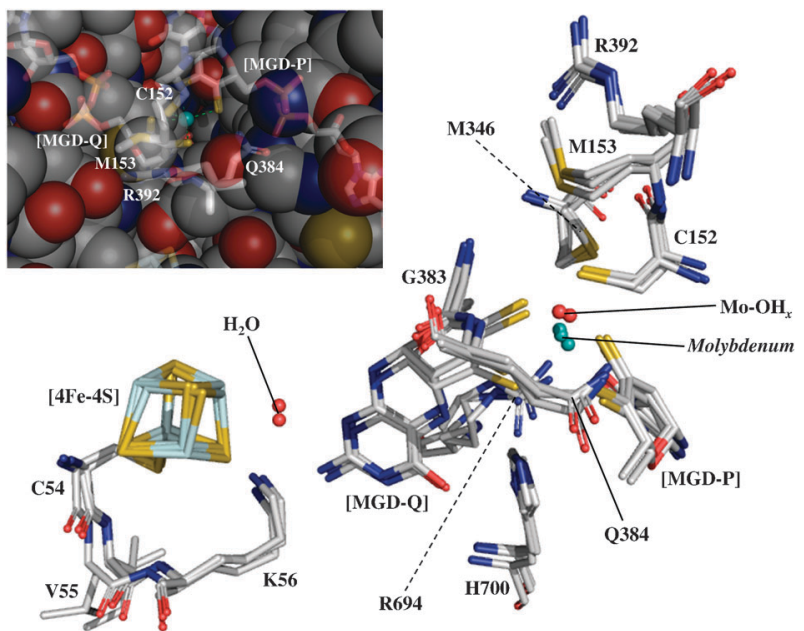

Fig. 10 Comparison of the active site region of NapA from E. coli (PDB: 2NYA), ${ }^{84}$ D. desulfuricans (PDB: $\left.2 \mathrm{NAP}\right)^{85}$ and $R$. sphaeroides (PDB: 1OGY). ${ }^{16}$ Amino acid numbering is as for R. sphaeroides NapA and the molybdopterin groups of the molybdopterin guanine dinucleotide (MGD) Q- and P-cofactors are indicated. Structures were superimposed relative to the structural coordinates of the $D$. desulfuricans protein using the crystallographic analysis program 'Superpose' from the CCP4 program suite (version 6.0.2). Structural overlay R.M.S. deviation was $1.37 \pm 0.02 \AA^{2}$ for $703 \pm 1$ conserved residue $\mathrm{C}_{\alpha}$ atoms. $\mathrm{An} \mathrm{Mo}-\mathrm{OH}_{x}$ species is resolved in the molybdenum coordination spheres of both the E. coli and D. desulfuricans NapA structures, as is a 'conserved' water molecule hydrogen-bonded to K56. Inset is the active site of NapA from $R$. sphaeroides seen from the protein surface. The $\mathrm{Mo}-\mathrm{OH}_{x}$ site lies directly at the bottom of a narrow substrate conducting channel.

there has been little consideration of the proton coupled electron transfer that accompanies the $\mathrm{Mo}(\mathrm{vI})=\mathrm{O}$ to $\mathrm{Mo}(\mathrm{Iv})$ transformation, nor the possibility of a rate-defining role for the $\mathrm{Mo}(\mathrm{v})$ oxidation state in catalysis. Extending the calculations to consider the complete enzyme structure through $\mathrm{QM} / \mathrm{MM}$ approaches is likely to be particularly informative. Activation energies for nitrate reduction by NarGH and Nas are $c a .37$ and $12 \mathrm{~kJ} \mathrm{~mol}^{-1}$, respectively, ${ }^{70}$ and similar values describe

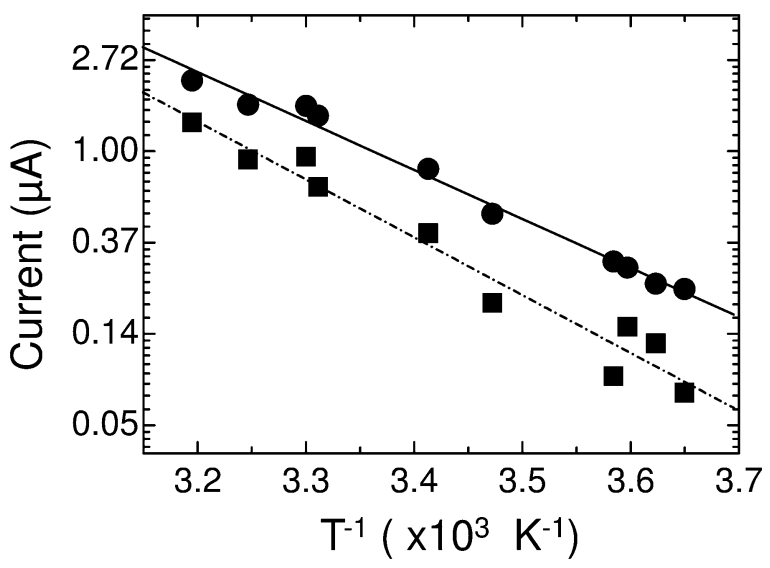

Fig. 11 Eyring plots for the maximal (circle) and attenuated (square) rates of $\mathrm{NapAB}$ nitrate reduction giving activation energies of $44.6 \pm 2$ and $52.7 \pm 4 \mathrm{~kJ} \mathrm{~mol}^{-1}$ respectively. Data collected for catalysis in $1 \mathrm{mM}$ nitrate at $\mathrm{pH} 6$. 
NapAB nitrate reduction at its maximal and attenuated rates, ca. 45 and $53 \mathrm{~kJ} \mathrm{~mol}^{-1}$, respectively, Fig. 11. The activation energies for nitrate reduction of functional analogs of the Mo active site are several orders of magnitude greater than those of for the catalysed reaction emphasising the contributions of the complete protein to defining the catalytic rate and, by implication, mechanism. To account fully for activity-potential relationships it will be necessary to couple active site chemistry to intramolecular electron transfer in addition to incorporating potential dependent interfacial electron transfer. We are not aware that this has been done yet. But QM/MM approaches that model intramolecular electron transfer in a manner that parallels Marcus theory may prove valuable in moving to this goal. $^{71-73}$

\section{Closing remarks}

We have chosen to focus on the steady-state activity-potential relationship of NapAB to illustrate the types of information afforded by PFE and their possible implications. However, we should not close without two further comments. PFE is not limited to the study of steady-state catalysis. Equivalent Perspectives could be written on the use of PFE to detect and elucidate non-steady-state catalysis in addition to noncatalytic redox events. In the former case this may afford insight into the mechanisms of metallocofactor assembly and protection against $\mathrm{O}_{2}$ damage. ${ }^{70,74,75} \mathrm{It}$ is also stimulating to see PFE expanding rapidly to provide fresh insight into integral membrane proteins incorporated within electrode supported bilayers that may be synthetic or part of living cells. $^{76,77}$ Thus, we are confident that PFE will continue to inform and stimulate studies of redox proteins for some time to come.

\section{Acknowledgements}

The authors would like to thank all those involved in research performed in their laboratories and the UK Biotechnology and Biological Sciences Research Council (BBSRC) for funding much of that research. The previously unpublished work presented here was funded by the BBSRC through $\mathrm{PhD}$ studentships (AJG and GLK) and grants C007808 and G009228.

\section{References}

1 P. Zuman, Analyst, 1992, 117, 1803-1809.

2 J. Heyrovsky, Nobel Lectures, Chemistry 1942-1962, Elsevier Publishing Company, Amsterdam, pp. 564-584.

3 M. J. Eddowes and H. A. O. Hill, J. Chem. Soc., Chem. Commun., 1977, 771-772.

4 K. Niki, T. Yagi, H. Inokuch and K. Kimura, J. Electrochem. Soc., 1977, 124, 1889-1891.

5 P. Yeh and T. Kuwana, Chem. Lett., 1977, 1145-1148.

6 F. A. Armstrong, Struct. Bonding, 1990, 72, 137-230.

7 F. A. Armstrong, H. A. O. Hill and N. J. Walton, Acc. Chem. Res., 1988, 21, 407-413.

8 J. E. Frew and H. A. O. Hill, Eur. J. Biochem., 1988, 172, 261-269.

9 F. A. Armstrong, Curr. Opin. Chem. Biol., 2005, 9, 110-117.

10 F. A. Armstrong, J. Chem. Soc., Dalton Trans., 2002, 661-671.

11 C. Léger, S. J. Elliott, K. R. Hoke, L. J. C. Jeuken, A. K. Jones and F. A. Armstrong, Biochemistry, 2003, 42, 8653-8662.
12 H. A. Heering, J. Hirst and F. A. Armstrong, J. Phys. Chem. B, 1998, 102, 6889-6902.

13 C. Léger and P. Bertrand, Chem. Rev., 2008, 108, 2379-2438.

14 C. Léger, A. K. Jones, S. P. J. Albracht and F. A. Armstrong, J. Phys. Chem. B, 2002, 106, 13058-13063.

15 A. J. Gates, D. J. Richardson and J. N. Butt, Biochem. J., 2008, 409, 159-168.

16 P. Arnoux, M. Sabaty, J. Alric, B. Frangioni, B. Guigliarelli, J. M. Adriano and D. Pignol, Nat. Struct. Biol., 2003, 10, 928-934.

17 C. C. Page, C. C. Moser, X. X. Chen and P. L. Dutton, Nature, 1999, 402, 47-52.

18 J. J. Davis and H. A. O. Hill, Chem. Commun., 2002, 393-401.

19 D. H. Murgida and P. Hildebrandt, Chem. Soc. Rev., 2008, 37, 937-945.

20 S. J. Marritt, G. L. Kemp, L. Xiaoe, J. R. Durrant, M. R. Cheesman and J. N. Butt, J. Am. Chem. Soc., 2008, 130, $8588-8589$.

21 V. Fourmond, B. Burlat, S. Dementin, M. Sabaty, P. Arnoux, E. Etienne, B. Guigliarelli, P. Bertrand, D. Pignol and C. Léger, Biochemistry, 2010, 49, 2424-2432.

22 B. A. C. Ackrell, F. A. Armstrong, B. Cochran, A. Sucheta and T. Yu, FEBS Lett., 1993, 326, 92-94.

23 S. Dementin, P. Arnoux, B. Frangioni, S. Grosse, C. Léger, B. Burlat, B. Guigliarelli, M. Sabaty and D. Pignol, Biochemistry, 2007, 46, 9713-9721.

24 G. L. Kemp, T. A. Clarke, S. J. Marritt, A. M. Hemmings, M. R. Cheesman, D. J. Richardson and J. N. Butt, Biochem. J., 2010, 431, 73-80.

25 B. C. Berks, D. J. Richardson, C. Robinson, A. Reilly, R. T. Aplin and S. J. Ferguson, Eur. J. Biochem., 1994, 220, 117-124.

26 C. S. Butler, J. M. Charnock, B. Bennett, H. J. Sears, A. J. Reilly, S. J. Ferguson, C. D. Garner, D. J. Lowe, A. J. Thomson, B. C. Berks and D. J. Richardson, Biochemistry, 1999, 38, 9000-9012.

27 C. S. Butler, J. M. Charnock, C. D. Garner, A. J. Thomson, S. J. Ferguson, B. C. Berks and D. J. Richardson, Biochem. J., 2000, 352, 859-864.

28 D. J. Richardson, Microbiology (Reading, U. K.), 2000, 146, 551-571.

29 M. F. Otten, W. N. M. Reijnders, J. J. M. Bedaux, H. V. Westerhoff, K. Krab and R. J. M. Van Spanning, Eur. J. Biochem., 1999, 261, 767-774.

30 M. F. Otten, D. R. Stork, W. N. M. Reijnders, H. V. Westerhoff and R. J. M. Van Spanning, Eur. J. Biochem., 2001, 268, $2486-2497$.

31 H. J. Sears, S. Spiro and D. J. Richardson, Microbiology (Reading, U. K.), 1997, 143, 3767-3774.

32 M. J. K. Ellington, K. K. Bhakoo, G. Sawers, D. J. Richardson and S. J. Ferguson, J. Bacteriol., 2002, 184, 4767-4774.

33 H. J. Sears, G. Sawers, B. C. Berks, S. J. Ferguson and D. J. Richardson, Microbiology (Reading, U. K.), 2000, 146, 2977-2985.

34 B. J. N. Jepson, L. J. Anderson, L. M. Rubio, C. J. Taylor, C. S. Butler, E. Flores, A. Herrero, J. N. Butt and D. J. Richardson, J. Biol. Chem., 2004, 279, 32212-32218.

35 C. Hunte, H. Palsdottir and B. L. Trumpower, FEBS Lett., 2003, $545,39-46$.

36 R. K. Thauer, K. Jungermann and K. Decker, Bacteriol. Rev., 1977, 41, 100-180.

37 H. V. Westerhoff, K. J. Hellingwerf and K. Vandam, Proc. Natl. Acad. Sci. U. S. A., 1983, 80, 305-309.

38 D. B. Kell, J. Gen. Microbiol., 1987, 133, 1651-1665.

39 L. J. Anderson, D. J. Richardson and J. N. Butt, Biochemistry, 2001, 40, 11294-11307.

40 M. Bekker, S. Alexeeva, W. Laan, G. Sawers, J. T. de Mattos and K. Hellingwerf, J. Bacteriol., 2010, 192, 746-754.

41 H. C. Angove, J. A. Cole, D. J. Richardson and J. N. Butt, J. Biol. Chem., 2002, 277, 23374-23381.

42 J. D. Gwyer, D. J. Richardson and J. N. Butt, J. Am. Chem. Soc., 2005, 127, 14964-14965.

43 E. Flores, J. E. Frias, L. M. Rubio and A. Herrero, Photosynth. Res., 2005, 83, 117-133.

44 E. Wang, M. C. Bauer, A. Rogstam, S. Linse, D. T. Logan and C. von Wachenfeldt, Mol. Microbiol., 2008, 69, 466-478. 
45 D. Georgellis, O. Kwon and E. C. C. Lin, Science, 2001, 292, 2314-2316.

46 A.L. Moore, I. B. Dry and J. T. Wiskich, FEBS Lett., 1988, 235, 76-80.

47 G. T. Hanson, R. Aggeler, D. Oglesbee, M. Cannon, R. A. Capaldi, R. Y. Tsien and S. J. Remington, J. Biol. Chem., 2004, 279, 13044-13053.

48 T. A. Clarke, G. L. Kemp, J. H. Van Wonderen, R. Doyle, J. A. Cole, N. Tovell, M. R. Cheesman, J. N. Butt, D. J. Richardson and A. M. Hemmings, Biochemistry, 2008, 47, 3789-3799.

49 L. J. Anderson, D. J. Richardson and J. N. Butt, Faraday Discuss., 2000, 116, 155-169.

50 S. J. Elliott, C. Léger, H. R. Pershad, J. Hirst, K. Heffron, N. Ginet, F. Blasco, R. A. Rothery, J. H. Weiner and F. A. Armstrong, Biochim. Biophys. Acta, 2002, 1555, 54-59.

51 L. Potter, H. Angove, D. Richardson and J. Cole, Adv. Microb. Physiol., 2001, 45, 51-112.

52 V. A. Bamford, H. C. Angove, H. E. Seward, A. J. Thomson, J. A. Cole, J. N. Butt, A. M. Hemmings and D. J. Richardson, Biochemistry, 2002, 41, 2921-2931.

53 R. Lin, M. Bayachou, J. Greaves and P. J. Farmer, J. Am. Chem. Soc., 1997, 119, 12689-12690.

54 C. E. Immoos, J. Chou, M. Bayachou, E. Blair, J. Greaves and P. J. Farmer, J. Am. Chem. Soc., 2004, 126, 4934-4942.

55 C. Costa, A. Macedo, I. Moura, J. J. G. Moura, J. Legall, Y. Berlier, M. Y. Liu and W. J. Payne, FEBS Lett., 1990, 276, 67-70.

56 P. Ramirez, N. Mano, R. Andreu, T. Ruzgas, A. Heller, L. Gorton and S. Shleev, Biochim. Biophys. Acta, 2008, 1777, 1364-1369.

57 B. Frangioni, P. Arnoux, M. Sabaty, D. Pignol, P. Bertrand, B. Guigliarelli and C. Léger, J. Am. Chem. Soc., 2004, 126, 1328-1329.

58 H. R. Pershad, J. Hirst, B. Cochran, B. A. C. Ackrell and F. A. Armstrong, Biochim. Biophys. Acta, 1999, 1412, 262-272.

59 V. Fourmond, M. Sabaty, P. Arnoux, P. Bertrand, D. Pignol and C. Léger, J. Phys. Chem. B, 2010, 114, 3341-3347.

60 J. Hirst, A. Sucheta, B. A. C. Ackrell and F. A. Armstrong, J. Am. Chem. Soc., 1996, 118, 5031-5038.

61 A. J. Gates, R. O. Hughes, S. R. Sharp, P. D. Millington, A. Nilavongse, J. A. Cole, E. R. Leach, B. Jepson, D. J. Richardson and C. S. Butler, FEMS Microbiol. Lett., 2003, 220, 261-269.

62 A. L. Tenderholt, R. K. Szilagyi, R. H. Holm, K. Hodgson, B. Hedman and E. Solomon, J. Inorg. Biochem., 2007, 101, 1594-1600.
63 A. L. Tenderholt, J. J. Wang, R. K. Szilagyi, R. H. Holm, K. O. Hodgson, B. Hedman and E. I. Solomon, J. Am. Chem. Soc., 2010, 132, 8359-8371.

64 E. J. Dridge and C. S. Butler, Biochimie, 2010, 92, 1268-1273.

65 J. Buc, C. L. Santini, R. Giordani, M. Czjzek, L. F. Wu and G. Giordano, Mol. Microbiol., 1999, 32, 159-168.

66 S. de Vries, M. Momcilovic, M. J. F. Strampraad, J. P. Whitelegge, A. Baghai and I. Schroder, Biochemistry, 2010, 49, 9911-9921.

67 P. L. Hagedoorn, W. R. Hagen, L. J. Stewart, A. Docrat, S. Bailey and C. D. Garner, FEBS Lett., 2003, 555, 606-610.

68 A. J. Healy, H. A. Reeve and K. A. Vincent, Faraday Discuss, 2011, 148, 345-357.

69 M. Hofmann, JBIC, J. Biol. Inorg. Chem., 2007, 12, 989-1001.

70 S. J. Field, N. P. Thornton, L. J. Anderson, A. J. Gates, A. Reilly, B. J. N. Jepson, D. J. Richardson, S. J. George, M. R. Cheesman and J. N. Butt, Dalton Trans., 2005, 3580-3586.

71 J. Blumberger and M. L. Klein, J. Am. Chem. Soc., 2006, 128, 13854-13867.

72 J. Blumberger and M. Sprik, J. Phys. Chem. B, 2005, 109, 6793-6804.

73 V. Tipmanee, H. Oberhofer, M. Park, K. S. Kim and J. Blumberger, J. Am. Chem. Soc., 2010, 132, 17032-17040.

74 V. Fourmond, B. Burlat, S. Dementin, P. Arnoux, M. Sabaty, S. Boiry, B. Guigliarelli, P. Bertrand, D. Pignol and C. Léger, J. Phys. Chem. B, 2008, 112, 15478-15486.

75 F. A. Armstrong, Photosynth. Res., 2009, 102, 541-550.

76 L. J. C. Jeuken, Nat. Prod. Rep., 2009, 26, 1234-1240.

77 E. Marsili, J. Sun and D. R. Bond, Electroanalysis (N. Y.), 2010, 22, 865-874.

78 L. A. Ridnour, J. E. Sim, M. A. Hayward, D. A. Wink, S. M. Martin, G. R. Buettner and D. R. Spitz, Anal. Biochem., 2000, 281, 223-229.

79 J. Sun, X. J. Zhang, M. Broderick and H. Fein, Sensors, 2003, 3, 276-284.

80 V. M. Ivanov, J. Anal. Chem., 2004, 59, 1002-1005.

81 S. S. Simons and D. F. Johnson, J. Org. Chem., 1978, 43, 2886-2891.

82 J. Mann, University of East Anglia, 2007.

83 G. L. Kemp, University of East Anglia, 2009.

84 B. J. N. Jepson, S. Mohan, T. A. Clarke, A. J. Gates, J. A. Cole, C. S. Butler, J. N. Butt, A. M. Hemmings and D. J. Richardson, J. Biol. Chem., 2007, 282, 6425-6437.

85 J. M. Dias, M. E. Than, A. Humm, R. Huber, G. P. Bourenkov, H. D. Bartunik, S. Bursakov, J. Calvete, J. Caldeira, C. Carneiro, J. J. G. Moura, I. Moura and M. J. Romao, Structure (London), $1999,7,65-79$. 